\title{
Forum Review
}

\section{Autophagy, Redox Signaling, and Ventricular Remodeling}

\author{
Narasimman Gurusamy and Dipak K. Das
}

\begin{abstract}
Autophagy is a catabolic process through which damaged or long-lived proteins, macromolecules, or organelles are recycled by using lysosomal degradation machinery. Although the occurrence of autophagy in several cardiac diseases including ischemic or dilated cardiomyopathy, heart failure, hypertrophy, and during ischemia/ reperfusion injury have been reported, the exact role of autophagy in these diseases is not known. Emerging studies indicate that oxidative stress in cellular system could induce autophagy, and oxidatively modified macromolecules and organelles can be selectively removed by autophagy. Mild oxidative stress-induced autophagy could provide the first line of protection against major damage like apoptosis and necrosis. Cardiac-specific loss of Atg5, an autophagic gene involved in the formation of autophagosome, causes cardiac hypertrophy, left ventricular dilation, and contractile dysfunction. Recently, it was revealed that Atg4, another autophagic gene involved in the formation of autophagosomes, is controlled through redox regulation under the condition of starvation-induced autophagy. In this review, we discuss the function of autophagy in association with oxidative stress and redox signaling in the remodeling of cardiac myocardium. Further research is needed to explore the possibilities of redox regulation of other autophagic genes and the role of redox signaling-mediated autophagy in the heart. Antioxid. Redox Signal. 11, 1975-1988.
\end{abstract}

\section{Introduction}

$\mathbf{I}^{\mathrm{x}}$ N RESPONSE to intrinsic or external stress, cardiac myocytes adopt a complex process involving molecular modifications and remodeling. Cardiac myocytes have long been considered terminally differentiated cells that cannot be replaced, unlike other cells such as intestinal epithelium, epidermal keratinocytes, or mature blood cells, which constantly undergo renewed cell division and differentiation. A cellulardegradation mechanism plays an important role in the homeostasis of cardiac cells $(87,90,109)$.

Two major pathways exist for the degradation of cellular materials: the ubiquitin-proteasomal pathway and autophagy. Most long-lived proteins, macromolecules, biologic membranes, and organelles, including mitochondria, ribosomes, endoplasmic reticulum, and peroxisomes, are turned over through autophagy, a process involving cellular lysosomal degradation machinery $(16,38,139)$. Autophagy can promote cell survival by generating free amino acids and fatty acids required to maintain function during nutrient-limiting conditions, or by removing damaged organelles and intracellular pathogens $(11,37,131)$. However, autophagy might also promote cell death through excessive self-digestion and degradation of essential cellular constituents $(3,15,118)$. Irreversibly damaged or diseased cells can initiate a self-killing program in the form of either apoptotic or autophagic cell death, followed by phagocytosis of cellular remains by neighboring cells, macrophages, or other scavengers $(19,37,79)$.

A variety of cellular stresses, such as endoplasmic reticulum stress or mitochondrial dysfunction, can induce autophagy $(43,49,51,141)$. Several reports indicate that oxidative stress mediated via reactive oxygen species (ROS) plays an important role in the myocardial repair/remodeling $(43,141)$.

Oxidative stress occurs when excess ROS are generated that cannot be adequately counteracted by the intrinsic antioxidant systems. Autophagy occurs at low levels under normal conditions and is important for the turnover of organelles (12, 157). Studies have shown that autophagy is upregulated in the heart in response to stress, such as ischemia/reperfusion $(13,41,43,111,131)$, and in many cardiovascular diseases, such as cardiac hypertrophy and heart failure $(22,29,37,38$, $133,139,157)$. Oxidative stress can induce autophagy under

Cardiovascular Research Center, University of Connecticut School of Medicine, Farmington, Connecticut. 
starvation and ischemia/reperfusion conditions (14, 62, 77, 119-121). The amino acid cysteine plays an essential role in the redox regulation of proteins via the thiol group present in cysteine (34). Thus, cysteine proteins can act as redox switches, to sense concentrations of oxidative stressors and to take part in important regulatory and signaling pathways $(33,34)$.

Recently, Scherz-Shouval et al. $(120,121)$ demonstrated that ROS act as signaling molecules in starvation-induced autophagy, in which ROS directly oxidize a cysteine residue in the cysteine protease Atg4, an autophagic gene regulating the formation of autophagosomes. Mild oxidative stress-induced soluble oxidized proteins are selectively degraded by chaperonemediated autophagy, which is mediated via the heat-shock protein, Hsc73 $(16,21,114)$. The purpose of this review is to discuss the role of autophagy and its association with oxidative stress-mediated redox signaling in ventricular remodeling.

\section{Autophagy}

To maintain cellular homeostasis, the eukaryotic cell system possesses two major degradation mechanisms, ubiquitinproteasomal degradation and autophagy. Autophagy (in Greek: self-digestion) under normal conditions occurs for the recycling of long-lived macromolecules and organelles via a lysosomal degradative pathway (70). Three types of autophagy exist: macroautophagy, microautophagy, and chaperonmediated autophagy.

Macroautophagy is the most active form of autophagy and is known to play a major role in intracellular degradation (16). Macroautophagy (hereafter referred to as autophagy) is initiated by the formation of an isolation membrane, a singlemembrane structure possibly derived from the sarcoplasmic/ endoplasmic reticulum (53). Fusion of the tips of the isolation membrane results in the formation of a double-membrane structure known as the autophagosome, which surrounds portions of the cytoplasm and organelles such as mitochondria $(16,140)$, selectively targeted to the toxic protein aggregates (110) or intracellular pathogens (40). Autophagosomes undergo a series of maturation steps and finally fuse with the lysosome (this combined structure is known as the autophagolysosome), in which the sequestered contents and the inner membranes of autophagosomes are degraded by the lysosomal hydrolases $(16,106)$. The lifetime of autophagosomes is as short as $\sim 8 \mathrm{~min}$.

In microautophagy, cytosolic macromolecules are locally taken into lysosome via invagination of the lysosomal membrane $(16,97)$. During chaperone-mediated autophagy, delivery of modified proteins to lysosome occurs via heat-shock protein 73 and the receptor lysosome-associated membrane protein type 2a (LAMP2a) $(16,17,59,84)$.

\section{Formation of autophagosomes}

Several autophagic genes are found to be regulated during the induction of autophagy. Autophagic genes are denoted as Atg, and they are further numbered (71). Atg12 is a small hydrophilic modifier protein, which is covalently conjugated to Atg5, independent of autophagy induction (95). Atg12 is activated by Atg7 in an ATP-dependent manner, resulting in the formation of thioester bond between the C-terminal gly- cine in Atg12 and a cysteine residue in Atg7 (95). The carboxyterminal glycine of Atg12 is transferred to Atg10, leading to the formation of a new thioester bond, and Atg7 is released. Atg10 activates the conjugation of carboxy-terminal glycine in Atg12 with lysine 149 in Atg5 (154). The formation of conjugation between Atg12 and Atg5 is irreversible and, at the same time, is essential for the formation of the autophagosome (154). Atg16 self-dimerizes and forms a complex with a pair of Atg12-Atg5 (32). Atg16 is found to bind only with Atg5, but not with Atg12 (32). This new complex, Atg12-Atg5Atg16, is vital for the elongation of the isolation membrane (Fig. 1) (96). At the end of autophagosome formation, the Atg12Atg5-Atg16 complexes dissociate from the membrane and are not present in the mature autophagosome $(16,96)$.

The development of the isolation membrane (phagophore) into the autophagosome requires the participation of microtubule-associated protein light-chain 3 (LC3) (135). LC3, the mammalian orthologue of Atg8, is synthesized as a cytosolic full-length precursor protein. Precursor LC3 is converted into LC3-I via cleavage by the cysteine protease Atg4 (autophagin), resulting in the exposure of glycine residue in the carboxy terminal of LC3-I (Fig. 1) (67). Atg7 activates the glycine residue of LC3-I in an ATP-dependent manner and finally is conjugated to phosphatidylethanolamine (PE) via an amide bond (83). The complex LC3-PE (or LC3-II) is then transferred to the outer autophagosomal membrane in an Atg5-dependent manner (96). LC3-II, in contrast to Atg12Atg5, is present both in the early phagophores and in the mature autophagosomes. Atg4 also converts LC3-II back to LC3-I via deconjugation of PE from LC3-II (54). Lysosomal proteases ultimately degrade most of the LC3-II found in autophagosomes (136).

In addition to LC3, another two mammalian homologues of yeast Atg8 are known: $\gamma$-aminobutyric acid type A receptorassociated protein (GABARAP) and Golgi-associated ATPase enhancer of $16 \mathrm{kDa}$ (GATE-16) $(112,145)$. GABARAP and GATE-16 also have been found to be associated with an autophagosomal membrane $(54,93)$. All these three mammalian Atg8 homologues possess a conserved glycine residue near their carboxy termini, which corresponds to the PE-acceptor site of yeast Atg8 (54). Four human homologues of Atg4 have been identified: autophagin 1 (HsAtg4B), autophagin 2 (HsAtg4A), autophagin 3, and autophagin 4 (83). GABARAP and GATE16 can be cleaved by either HsAtg4A or HsAtg4B, but LC3 is preferentially cleaved by HsAtg4B (54). Like LC3, it was suggested that GATE16 and GABARAP are also converted into form II (135).

In F9 teratocarcinoma cells, both GATE16 and GABARAP are detected in two forms (I and II); form I of both proteins is primarily cytosolic, whereas form II is associated in the membrane fraction $(54,55)$. The formation of both GATE-16-II and GABARAP-II has been increased under starvation, and further, they have been associated with the autophagosomal membrane $(54,55)$.

\section{Fusion of autophagosomes}

On completion of autophagic sequestration, the autophagosome undergoes multistep maturation, leading to fusion with endosomal vesicles and protease-containing late endosomal compartments and finally with lysosomes (Fig. 1) (36). 


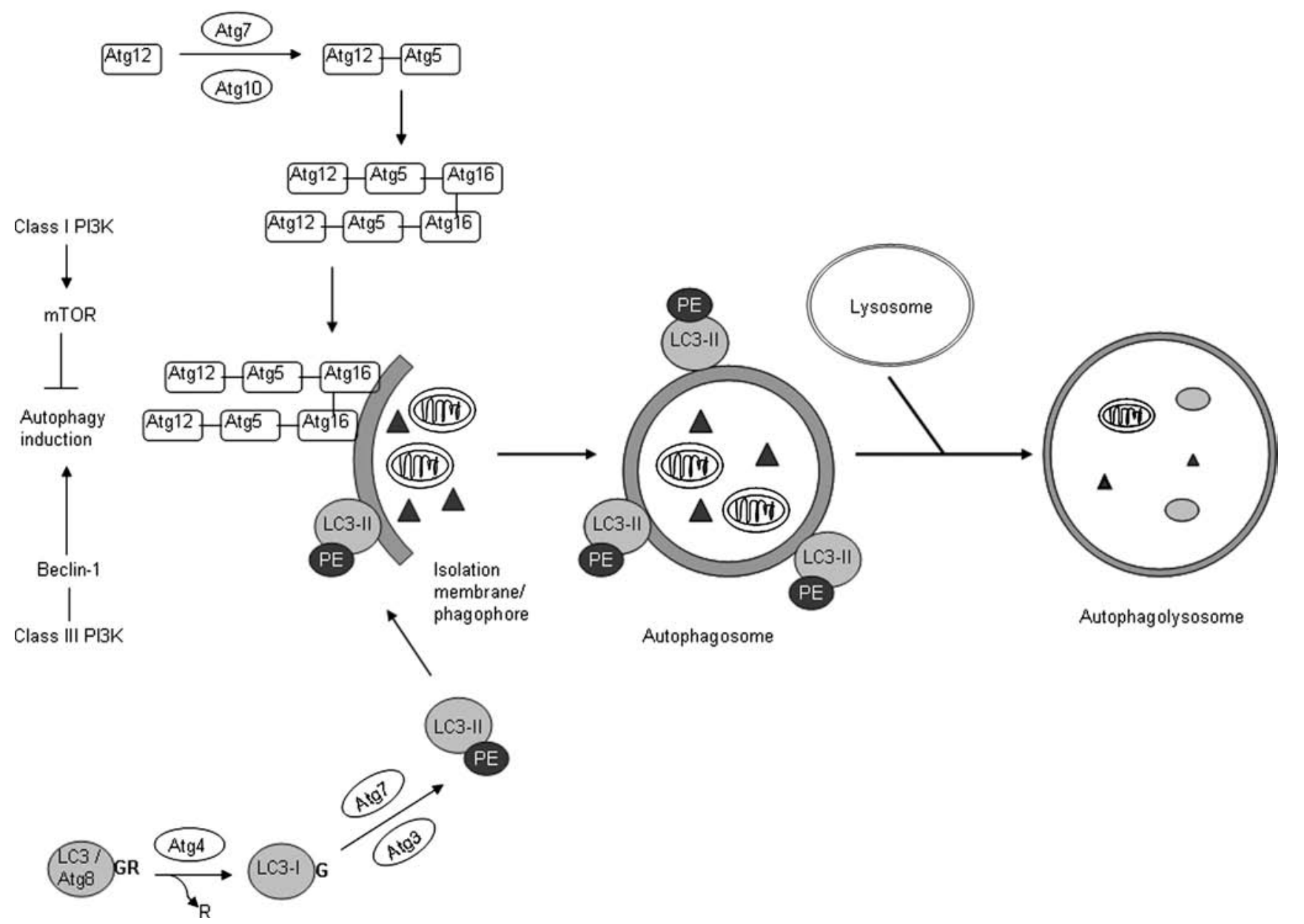

FIG. 1. Process of macroautophagy. First step in the process of macroautophagy involves the formation of a doublemembrane structure called the isolation membrane or phagophore, composed of the complex Atg12-Atg-5-Atg16 and LC3-II. Atg12 is activated by Atg7 and Atg10, resulting in the conjugation with Atg5. Homodimers of Atg16 bind a pair of Atg12-Atg5, and the complex Atg12-Atg5-Atg16 then associates with the autophagosomal membrane. Atg4 cleaves LC3/Atg8, generating LC3-I, with exposure of the C-terminal glycine residue. LC3-I is then activated by Atg7 and Atg3, and conjugated to phosphatidylethanolamine (PE), forming LC3-II, which is then bound to the autophagosomal membrane. An isolation membrane engulfs a portion of cytosol containing damaged proteins or organelles, forming the structure known as the autophagosome. The autophagosome fuses with a lysosome, forming an autophagolysosome, in which the damaged proteins or organelles are degraded by lysosomal proteases.

The fusion events are mediated in part by a family of Rab guanosine triphosphatases, known mediators of vesicular trafficking. Rab7 is shown to be a key component in the regulation of autophagosomal maturation (39). Lysosomalreceptor proteins Lamp1 and Lamp2 are involved in Rab7mediated fusion of autophagosomes and lysosomes (52). Through fusion with a lysosome, an autophagosome acquires the milieu and enzymes necessary for the degradation of its cargo.

Lysosomes contain a cocktail of predominantly hydrolytic enzymes that are maximally activated at low $\mathrm{pH}$ (e.g., cathepsins B and D, which degrade proteins, lipids, nucleic acids, and polysaccharides) (147). Autophagy-mediated recycling of degraded products (amino acids, sugars, and nucleotides) is achieved via lysosomal transport proteins such as cystinosin, which transfer the degraded products from the lysosome back to the cytosol (147), and thus the catabolic process is completed.

\section{Detection of autophagy}

Formation of double-layered autophagosomes can be monitored by electron microscopy (92), but lack of morphologic expertise can lead to misidentification of other cellular structures, such as swollen endoplasmic reticulum (in dying cells) as autophagosomes. In some cases, monodansylcadaverine has been used as a fluorescent marker for autophagic vacuoles (7); however, this method is limited to in vivo conditions. LAMP-2a has been used as a marker to study chaperone-mediated autophagy (20). However, at present, only LC3 is the credible marker to study autophagosome formation. LC3 is found to be present in both the isolation membrane and the autophagosome (55); the conversion of LC3 to LC3-I and LC3-II can be studied with Western blotting. The generation of transgenic mice expressing green fluorescent protein fused to LC3 becomes a useful tool to study autophagic activity in vivo (94). 


\section{Regulation of autophagy}

A great number of extracellular stimuli (starvation, hormone, or therapeutic treatment) as well as intracellular stimuli (accumulation of misfolded proteins, invasion of microorganisms) are able to modulate the autophagic response (15). Nutrient deprivation is the most generalized stimuli for macroautophagy. However, a decrease in specific regulator amino acids and increased levels of glucocorticosteroids and thyroid hormone also stimulate macroautophagy (153). Insulin, various growth factors, cyclic adenosine monophosphate (AMP), and cyclic guanosine monophosphate (GMP) as well as conditions that lead to reduced intracellular levels of adenosine triphosphate (ATP) are known as physiologic inhibitors of autophagy (153). However, glucagon and $\beta$ adrenergic agonists inhibit rather than stimulate autophagy in cardiac and skeletal muscle (139).

Amino acids that are the final products of autophagic protein degradation act as negative-feedback regulators for the process. A combination of leucine and a few other amino acids is very effective in inhibiting autophagy (6). Addition of amino acids has been shown to phosphorylate ribosomal protein S6 kinase (S6K) and 4E-binding protein 1 (4E-BP1) (6). Amino acids and insulin act synergistically on both processes to inhibit autophagy (8). In the presence of amino acids and growth factors, the mammalian target of rapamycin (mTOR) activates the p70 S6K, which phosphorylates the ribosomal protein S6, resulting in the upregulation of the translational machinery (6). 4E-BP1 is an inhibitor of translation that can be directly phosphorylated by mTOR, leading to the deactivation of 4E-BP1 (15). Deactivated 4E-BP1 then dissociates from the initiation factor eIF4E, which is the rate-limiting step in protein synthesis. Free eIF4E binds to the $5^{\prime}$ terminal cap structure of RNAs and promotes the progress of translation (15).

Inhibiting mTOR activity with the immunosuppressant rapamycin increases the catabolic process of autophagy (8). p70 S6K is needed for the entire process of autophagy activation, and it must be activated first for maximal activation of autophagy (123).

Activation of TOR signaling negatively regulates the association between Atg13 and Atg1. Under nutrient-rich conditions, active TOR causes hyperphosphorylation of Atg13, inhibiting its association with Atg1 $(56,124)$. Starvation or rapamycin treatment inactivates $\mathrm{TOR}$, leading to rapid dephosphorylation of Atg13, which promotes the binding with Atg1. This association promotes autophosphorylation and activation of Atg1, leading to the induction of autophagy $(56,124)$.

Depletion of ATP is associated with an increase in AMP. AMP-activated protein kinase (AMPK), which serves as a general integrator of metabolic responses to changes in energy availability, is activated in response to elevations of the AMP/ATP ratio (115). TOR can act not only as an amino acid sensor, but also as an ATP sensor (101) Recently, it was shown that glucose deprivation in cardiac cells and cardiac ischemia activate AMPK, leading to the activation of autophagy (85, 132).

Autophagy was shown to be regulated through class III and class I phosphatidylinositol 3-kinases (PI3K) pathways. Class I PI3-K suppresses autophagy, whereas class III PI3-K activates autophagy. Beclin1/Atg6, the first mammalian protein described to mediate autophagy (81), by forming a complex with Vps34, a class III PI3-K, positively regulates autophagy $(65,156)$. The Beclin 1/PI3K-III complex is involved in the formation of autophagosomes and the initiation of autophagy (156). PI3K-III inhibitors like 3-methyl adenine, wortmannin, and LY294002 interfere with this pathway (9). Beclin 1 has been shown to colocalize with the sarcoplasmic/ endoplasmic reticulum, mitochondria (80), and Golgi (65). Furthermore, the yeast homologues of Beclin 1 and Vps34 have been shown to mediate intracellular vesicle trafficking, including endosomes, and transport of lysosomal proteases from the Golgi to the lysosome $(64,102)$.

\section{ROS and Redox Signaling in Autophagy}

As mentioned earlier, autophagy is a unique catabolic pathway in eukaryotic cells, inducible by a variety of intracellular and extracellular stimuli such as starvation, environmental stress, damaged protein or organelles, and pathogenic infections for the degradation and recycling of macromolecules and long-living organelles. However, the exact molecular mechanism that induces autophagy under these stimuli is not known.

Recently, Scherz-Shouval et al. (121) showed that ROS generated during starvation act as signaling molecules to initiate autophagosome formation and autophagic degradation. Oxidative stress can induce autophagy under starvation and ischemia/reperfusion conditions (14, 62, 77, 119-121). Increasing evidence suggests that ROS play an important role in the induction of autophagy. For example, ROS are involved in the induction of neuronal autophagic cell death after withdrawal of nerve growth factor $(68,150)$. In Parkinson disease, oxidation of dopamine induces autophagy (35). In yeast, ROS-mediated lipid oxidation of mitochondria has been shown to induce autophagy (69). Tumor necrosis factor$\alpha$ induces autophagy in an ROS-dependent mechanism (23). In plant cells, oxidative stress-induced oxidized proteins are removed through autophagy (148).

ROS are highly reactive oxygen-based chemical species, which include free radicals (superoxide and hydroxyl radicals, which have one or more unpaired electrons in the outer orbit) and nonradicals capable of generating free radicals, such as hydrogen peroxide. ROS are normally produced in cells during oxidative phosphorylation and play a role in redox control of physiologic signaling pathways (98). Excessive ROS can induce oxidation and damage to DNA, lipids, proteins, and other macromolecules (98). Intracellular ROS can be produced either through electron leakage during mitochondrial oxidative phosphorylation or through the activation of several cellular enzymes, including nicotinamide adenine dinucleotide phosphate (NADPH) oxidase, xanthine oxidase, and nitric oxide synthase (117). Superoxide is formed intracellularly by the activation of either NADPH oxidase or xanthine oxidase $(98,117)$, and it can rapidly react with nitric oxide to form $\mathrm{ONOO}^{-}$or convert into $\mathrm{H}_{2} \mathrm{O}_{2}$ to form hydroxyl radical (57).

The intracellular redox state is characterized by the balance of oxidant production and the antioxidant capacity of the cell, based on a variety of antioxidant enzymes such as superoxide dismutase (which reduces superoxide into $\mathrm{H}_{2} \mathrm{O}_{2}$ ), catalase, as well as glutathione peroxidase (which reduces $\mathrm{H}_{2} \mathrm{O}_{2}$ to $\mathrm{H}_{2} \mathrm{O}$ ). The nonenzymatic antioxidant molecules include vitamin $\mathrm{E}$, 
vitamin $C, \beta$-carotene, ubiquinone, lipoic acid, and urate (30). The thioredoxin system, including thioredoxin, thioredoxin reductase, and NADPH, forms an additional integrated antioxidant defense system, which operates as a powerful protein-disulfide oxidoreductase (60). At lower concentrations, ROS serve as second messengers that transmit biologic information, which is known as redox signaling. Redox signaling processes are involved in the activation of many signal-transduction protein kinases and transcription factors, the stimulation of DNA synthesis, and expression of growth-related genes (48).

\section{Redox regulation by cysteine}

The amino acid cysteine plays an essential role in the redox regulation of proteins through the thiol group present in cysteine. A number of cysteine-containing proteins, such as the thioredoxins, and enzymes, such as glutathione reductase, require redox-active cysteine residues for their activity (1, 105). Oxidative modification of cysteine residues in proteins influences the activity of many proteins (149) and has been implicated in cellular signaling and regulatory pathways (27). Cysteines can undergo various redox-dependent modifications, such as formation of disulfide bonds, S-nitrosylation, and the formation of sulfenic, sulfinic, and sulfonic acid, and sulfur-centered radicals (34). The low redox potential of cysteine allows rapid electron transfer from cysteine, resulting in thiyl radical and disulfide formation $(33,34)$.

The reverse reaction, for example, occurs in proteins such as human glutathione disulfide reductase and thioredoxin reductase, in which a two-electron transfer from the reduced form of flavin adenine dinucleotide reduces a cystine disulfide bond to two cysteine thiols (99). Changes in the cellular redox balance trigger signal-transduction pathways by modifying the oxidation state of cysteine residues in participating proteins. Redox modifications can exert a variety of effects on proteins ranging from inactivation of a catalytic residue to extensive structural changes $(28,33)$. Cysteine-harboring proteins serve as redox sensors, and they can undergo rapid and reversible posttranslational modifications in response to changes in the oxidative stress of the environment (33). Although many cysteine modifications irreversibly abolish protein function, the reversible (e.g., $S$-thiolation, sulfenic acid formation) and some of the irreversible (e.g., sulfinic and sulfonic acid formation) modifications have been recently considered to play a regulatory role during normal cell function, apoptosis, aging processes, and oxidative stress $(27,34)$.

\section{Redox regulation in autophagy}

Atg4s are cysteine proteases that share several conserved cysteine residues. Atg4s cleave Atg8s near the C-terminus, downstream of a conserved glycine (82). This cleavage allows the conjugation of Atg8 (LC3) to PE through the exposed glycine, a process mediated through a ubiquitination-like mechanism (67). Atg8-PE serves as another substrate for Atg4, which cleaves Atg8 and releases it from the autophagosomal membrane $(67,137)$. In the process of autophagy, after initial cleavage of Atg8-like proteins, Atg4 must become inactive to ensure the conjugation of Atg8 to the autophagosomal membrane. Later, as the autophagosome fuses with lysosome, Atg4 must be locally reactivated to delipidate and recycle Atg8.
In mammalian cells, amino-acid deprivation induces lipidation of LC3 as well as of GATE-16 and GABARAP $(54,55)$. Lipidated Atg8s associate with phagophores and autophagosomes and remain there until fusion with lysosomes, at which point intraautophagosomal Atg8 is probably degraded $(54,55)$. Recently, Atg 4 was shown to be regulated by a redoxdependent mechanism during starvation-induced autophagy, in which the conjugation (lipidation) reaction of Atg4 is not being affected, but the deconjugation (delipidation) activity of Atg4 is redox regulated (121). Through in vitro studies, it has been demonstrated that a reducing environment activates the delipidation reaction of Atg4, but the oxidizing environment reversibly inactivates the delipidation reaction of Atg4 (121).

Starvation induces the formation of $\mathrm{H}_{2} \mathrm{O}_{2}$, a process which is partially dependent on class III PI3 kinase, leading to the inactivation of Atg4 at the site of autophagosome formation, and inactivation of Atg4 causes the accumulation of lipidated form of Atg8 (121). Redox regulation of several cysteine proteases, including cathepsin D, cathepsin B, and the cytosolic caspase-3, as well as calpains, has been shown to occur through a direct modification of the active site (34). Thus, redox regulations of Atg 4 can cause rapid activation and inactivation of this protease, leading to induction of the autophagic process.

At least four Atg4 mammalian homologues have been reported. Two of the homologues, HsAtg4A and HsAtg4B, were shown to cleave the three mammalian Atg8s with different efficiencies: HsAtg4A cleaves mainly GATE-16, whereas HsAtg4B cleaves all three homologues (GATE-16, GABARAP, and LC3), with the highest efficiency for LC3 (54). Atg4A contains 12 cysteines, seven of which are highly conserved among tetrapod homologues of Atg4A and Atg4B. In vitro experiments show that cysteine 81 , but not cysteine 77 , in Atg4 is important for redox regulation, in which mutation of cysteine 81 to serine significantly impaired the redox activity of Atg4A and abolished the formation of GATE-16labeled autophagosomes in cells (121). This study (121) indicated that oxidative conditions are essential for autophagy, as treatment with antioxidative agents abolished the formation of autophagosomes. Furthermore, the cysteine protease $\mathrm{HsAtg} 4$ is a direct target for oxidation by $\mathrm{H}_{2} \mathrm{O}_{2}$, and a cysteine residue located near the HsAtg4 catalytic site acts as a critical regulator (121). Atg4 shares a high level of structural homology with the papain superfamily (129), in which the cysteine is oxidized to sulfenic acid (107). In the same manner, Atg4 can be oxidized to sulfenic acid by $\mathrm{H}_{2} \mathrm{O}_{2}$. Although the formation of a disulfide bridge was not detected in the study of ScherzShouval et al. (121), the authors suggested the possibility of formation of a disulfide bridge between the catalytic cysteine (Cys77 or Cys74 of HsAtg4A or HsAtg4B, respectively) and the regulatory cysteine residue (Cys81 or Cys78 of HsAtg4A or HsAtg4B, respectively).

\section{Oxidative stress and autophagy}

Oxidatively modified macromolecules often crosslink with other proteins, lipids, carbohydrates, or metals, forming a brownish pigment known as lipofuscin (138). Lipofuscin, a biomarker of aging, is an autofluorescent pigment that accumulates during aging in the lysosomal lumen of postmitotic cells (138). The formation of lipofuscin requires the presence of $\mathrm{H}_{2} \mathrm{O}_{2}$ and ferrous iron in the lysosomal lumen. $\mathrm{H}_{2} \mathrm{O}_{2}$ 
generated by mitochondria and other organelles permeates into the lumen of secondary lysosomes (138). These lysosomes contain iron derived from cellular structures undergoing autophagic degradation. Diffusion of hydrogen peroxide into the lysosomes results in Fenton-type reactions with the formation of hydroxyl radicals and ensuing peroxidation of lysosomal contents with formation of lipofuscin (16).

Increased levels of oxidative stress also were shown to accumulate another autofluorescent pigment known as ceroid (58). The normal accumulation of lipofuscin in lysosomes seems to reduce the autophagic capacity of senescent postmitotic cells, which resulted in an insufficient autophagy, causing accumulation of damaged cellular components (16).

Oxidative stress enhanced the formation of hydroxyl radicals within lysosomes that risks the membrane stability of iron-rich lysosomes and autophagolysosomes $(16,62)$. Cells experimentally loaded with lipofuscin showed an increased susceptibility to oxidative stress, leading to lysosomal membrane breakage $(16,62)$. Nutrient deprivation in cells induces autophagy, which causes an increase in the availability of ferric iron pool, resulting in the increased sensitivity of cells to oxidative stress (103). The rupture of a limited number of lysosomes has been recognized as an early upstream event in many cases of apoptosis, particularly oxidative stress-induced apoptosis, whereas necrosis results from a major lysosomal break (10). Thus, the regulation of the lysosomal content of redox-active iron seems to be essential for the survival of cells in both the short and the long term. Oxidative stress can affect the permeability of the lysosomal membrane by inducing the crosslinking of lysosomal membrane proteins via disulphide bonds; it results in increased lysosomal proton permeability, luminal $\mathrm{pH}$, and membrane potential (144). These results show that the redox status of the lysosomal membrane thiol groups influence its permeability (144).

Although autophagy is nonselective under oxidative conditions, it is an efficient mechanism in removing oxidatively damaged mitochondria, peroxisomes, and endoplasmic reticulum (66). Oxidative damage increases the permeability and depolarization of the mitochondrial membrane and results in leakage of intramitochondrial components such as cytochrome $c$, which initiates programmed cell death (2). Macroautophagy protects cells from major harm by removing the damaged mitochondria at an early stage (78). This protective macroautophagy is considered to be the crossroad between cell death and survival (125). Death-associated protein kinase and tumor necrosis factor-related apoptosisinducing ligand are the two molecules that have been shown to be involved in the activation of both autophagy and apoptosis in a caspase-dependent or -independent manner (104). At low levels, these factors may induce macroautophagy; however, if the activated autophagy is insufficient to remove the cellular damage, the intracellular level of the two death factors would remain high to induce cell death. It is clear from these results that protective macroautophagy truly draws a borderline between cell survival and cell death, when autophagy and apoptosis are governed by the extent of oxidative stress.

Chaperone-mediated autophagy participates under mild oxidative-stress conditions by the removal of soluble and oxidatively modified proteins from the cytosol (63). During chaperone-mediated autophagy, oxidized substrate proteins are directly translocated into the lysosomal lumen (63). Oxi- dative modification of proteins facilitates the exposure of the lysosomal targeting motif, KFERQ, which is recognized through Hsc73 (20, 21). The substrate/chaperone complex is translocated into the lysosomal lumen via interaction with LAMP2a, a receptor protein present in the lysosomal membrane (26). Studies have shown that the lysosomal ability to internalize substrates is enhanced during mild oxidative stress in cultured cells and in animals (63).

Microautophagy refers to the formation of lysosomal membrane invaginations, which sequester the contents of cytoplasm and degrade them intralysosomally (16). Microautophagy is a constitutive mechanism for the continuous degradation of long-lived proteins inside many types of cells (16). However, the molecular mechanisms of microautophagy have not been well characterized. Although starvation has been shown to induce both macroautophagy and chaperonemediated autophagy (16), the molecular events directing the autophagic route toward macroautophagy, microautophagy, and chaperone-mediated autophagy are not well understood. It is possible that the extent of oxidative stress may play a role in this process.

A genomic study by Thorpe et al. (142) showed that autophagic genes have been upregulated in response to protection against reactive oxygen species in Saccharomyces cerevisiae. Recently, Chen et al. (14) demonstrated that oxidative stress caused by treatment with $\mathrm{H}_{2} \mathrm{O}_{2}$ induces autophagic cell death in transformed and cancer cell lines. Inhibition of autophagosome accumulation through treatment with 3-methyl adenine and knocking down the genes involved in autophagy, such Beclin-1, Atg5, and Atg7, by treatment with respective siRNAs effectively blocked the oxidative stressinduced autophagic cell death. Inhibiting ROS generation by treatment with the ROS scavenger tiron inhibited autophagic cell death. Further, it was demonstrated that $\mathrm{H}_{2} \mathrm{O}_{2}$-induced autophagic cell death is independent of apoptosis (14). Yu et al. (155) showed that inhibition of caspase induces the degradation of catalase, leading to the accumulation of ROS and autophagic cell death. Taken together, these studies clearly indicate the role of ROS in the induction of autophagy.

\section{Autophagy in Ventricular Remodeling}

Autophagy in cardiac myocytes was first reported by Sybers et al. in 1976 (130), approximately one decade after the initial description of autophagy in mammalian cells (18). In the study of Sybers et al. (130), the formation of autophagic vacuoles was revealed through electron microscopy, which showed the presence of damaged organelles within autophagic vacuoles. This process was accelerated by transient deprivation of oxygen and glucose, followed by resupply of oxygen and glucose (130).

A disturbed balance between a high rate of ubiquitination and inadequate degradation of ubiquitin/protein conjugates contributes to autophagic cell death in failing human hearts (73). Autophagic cell death in cardiac tissue of patients in the terminal stage of heart failure, as a consequence of either ischemic cardiomyopathy or dilated cardiomyopathy (DCM), was demonstrated by granular cytoplasmic ubiquitin inclusions, an established marker of autophagocytosis (72). Interestingly, these autophagic cardiomyocytes were not only terminal dUTP nick-end labeling (TUNEL) and activated caspase-3 negative but also were negative for $\mathrm{C} 9$, a marker for 
necrosis (72). The results of this study reveal that cardiomyocytes in heart failure show caspase-independent autophagic cell death rather than apoptotic cell death (72). Recently, dead and dying cardiomyocytes showing characteristics of autophagy were reported in heart failure caused by DCM and valvular and hypertensive heart disease (22).

Hein et al. $(46,47)$ showed that progression from compensated hypertrophy to heart failure and left ventricular systolic dysfunction in the pressure-overloaded human heart involves cell loss, mainly by autophagy and oncosis. In the myocardium of patients with DCM, autophagy appears to be associated not only with degradation of damaged intracellular organelles but also with progressive destruction of cardiomyocytes (126). Strong staining for LAMP-1 and cathepsin D indicated increased activity of lysosomal functions in atrophic and degenerated cardiomyocytes (126). These degenerated cardiomyocytes were mostly adjacent to the area with massive replacement fibrosis and fatty tissue, where cardiomyocyte loss was highly indicative. Both electron microscopy and immunohistochemistry indicated that autophagic and lysosomal functions may contribute to cellular atrophy and the destruction leading to cell death, as well as the degradation of damaged intracellular organelles (126).

Yan et al. $(151,152)$ found that in chronically ischemic myocardium, a significant increase is seen in the expression of autophagic marker proteins, including cathepsin D, cathepsin $\mathrm{B}$, heat-shock cognate protein Hsc73 (a key protein marker for chaperone-mediated autophagy), Beclin 1, and LC3. It was shown that the myocytes containing autophagic vacuoles are observed in chronically ischemic myocardium in live, but not in lysed cells. In contrast, autophagic markers are downregulated in infarcted myocardium. Apoptosis is maximal after three episodes of ischemia, but declined markedly after six episodes (152). The appearance of autophagy becomes evident after three episodes of ischemia and is fully manifest after six episodes of ischemia. Immunostaining of cathepsin B is much more abundant in myocytes in nonapoptotic regions, but myocytes in apoptotic regions rarely stained positive for cathepsin B (152). Such evidence suggests that autophagy triggered by ischemia could be a homeostatic mechanism, by which apoptosis is inhibited and the deleterious effects of chronic ischemia are limited $(151,152)$.

In human hibernating myocardium, ubiquitin-related autophagic cell death was identified by the occurrence of autophagic vacuoles, cellular degeneration, and nuclear disassembly. In addition to ubiquitin-related autophagic cell death, loss of myocytes by apoptosis also was observed in hibernating myocardium $(24,25)$. In a case of unclassified cardiomyopathy, prominent autophagic degeneration was accompanied by an elevated level of plasma brain natriuretic peptide $(600 \mu \mathrm{g} / \mathrm{ml})$ despite the lack of overt heart failure. Immunohistochemical and electron-microscopic analysis revealed the staining of BNP and the presence of autophagosomes, respectively (113). In a hamster model of human dilated cardiomyopathy, autophagic degeneration of cardiomyocytes led to cell death (133). Treatment with granulocyte colony-stimulating factor (G-CSF) significantly improved survival and remodeling, which was accompanied by a reduction in autophagy (133). G-CSF treatment induced the activation of Akt and signal transducer and activator of transcription-3, followed by a reduction in the level of myocardial tumor necrosis factor- $\alpha$ (133). Recently, it was shown that pressure overload, a major risk factor for cardiac hypertrophy and heart failure, triggers basal autophagy, particularly in the basal septum (157).

Autophagy plays a crucial role in normal heart function and serves as a catabolic energy source during starvation. Autophagy in cardiac myocytes has been suggested to provide a necessary source of energy between birth and suckling (76). Cardiac myocytes from starved animals display high numbers of autophagosomes, which aid in cell survival in the adverse conditions of nutrient deprivation (94). Apart from cardiomyocytes, autophagy also occurs in interstitial cells of the aortic valves of patients with severe aortic-valve stenosis $(91,128)$, in which cell death in the calcification of aortic leaflets is shown to be caused by autophagy rather than apoptosis. The relation between cell growth and autophagic vacuole volume during cardiac hypertrophy induced by supravalvular aortic constriction indicates that the degradation of cytoplasmic components by autophagy is inhibited in cardiomyocytes undergoing hypertrophy $(91,128)$. Such an anticatabolic reaction seems to play an important role in establishing the positive balance of cellular metabolism generally required for growth processes.

Cardiac-specific loss of Atg5 in mice led to cardiac hypertrophy, left ventricular dilatation, and contractile dysfunction, accompanied by increased levels of ubiquitination (100). Moreover, Atg5-deficient hearts showed disorganized sarcomere structure and mitochondrial aggregation. Under baseline conditions, cardiac-specific deficiency of Atg5 in early cardiogenesis does not show any abnormalities but develops cardiac dysfunction and left ventricular dilatation 1 week after pressure overload (100). These results indicate that, under baseline conditions, constitutive autophagy in the heart is a homeostatic mechanism for maintaining cardiomyocyte size and global cardiac structure and function, and that upregulation of autophagy in failing hearts is an adaptive response for protecting cells from hemodynamic stress (100). The embryonic Atg5-knockout mice are viable and live to adulthood without any detectable heart abnormalities (100), presumably owing to compensatory mechanisms that also perform cellular maintenance. Defective autophagic degradation owing to the deficiency of LAMP-2 in mice manifested a vacuolar cardioskeletal myopathy leading to severe cardiac dysfunction, a disorder also known as Danon disease (134).

Cardiac ischemia and glucose deprivation in cardiac myocytes induce autophagy via activation of AMPK, a sensitive nutrient sensor $(85,86)$. In contrast, autophagy induced during the reperfusion phase is accompanied by the upregulation of Beclin 1, but not by AMPK activation $(85,86)$. Glucose deprivation has been shown to increase AMPK and eEF2 phosphorylation and to decrease p70S6K and mTOR phosphorylation (85). Apart from being a sensor of amino acids, mTOR also can sense changes in the cellular energy state via AMPK (88). In yeast and mammalian cells, activation of AMPK was shown to stimulate autophagy (127, 146). Activation of AMPK inhibits mTOR-dependent signaling and protein synthesis, (88) which are consistent with the AMPK function of switching off ATP-dependent processes (45). In contrast, activation of AMPK by addition of the cell-permeable nucleotide analogue 5-amino-4-imidazole carboxamide riboside and N6-mercaptopurine in hepatocytes strongly inhibits autophagy $(115,116)$. Insulin signaling is known to activate mTOR leading to the suppression of 


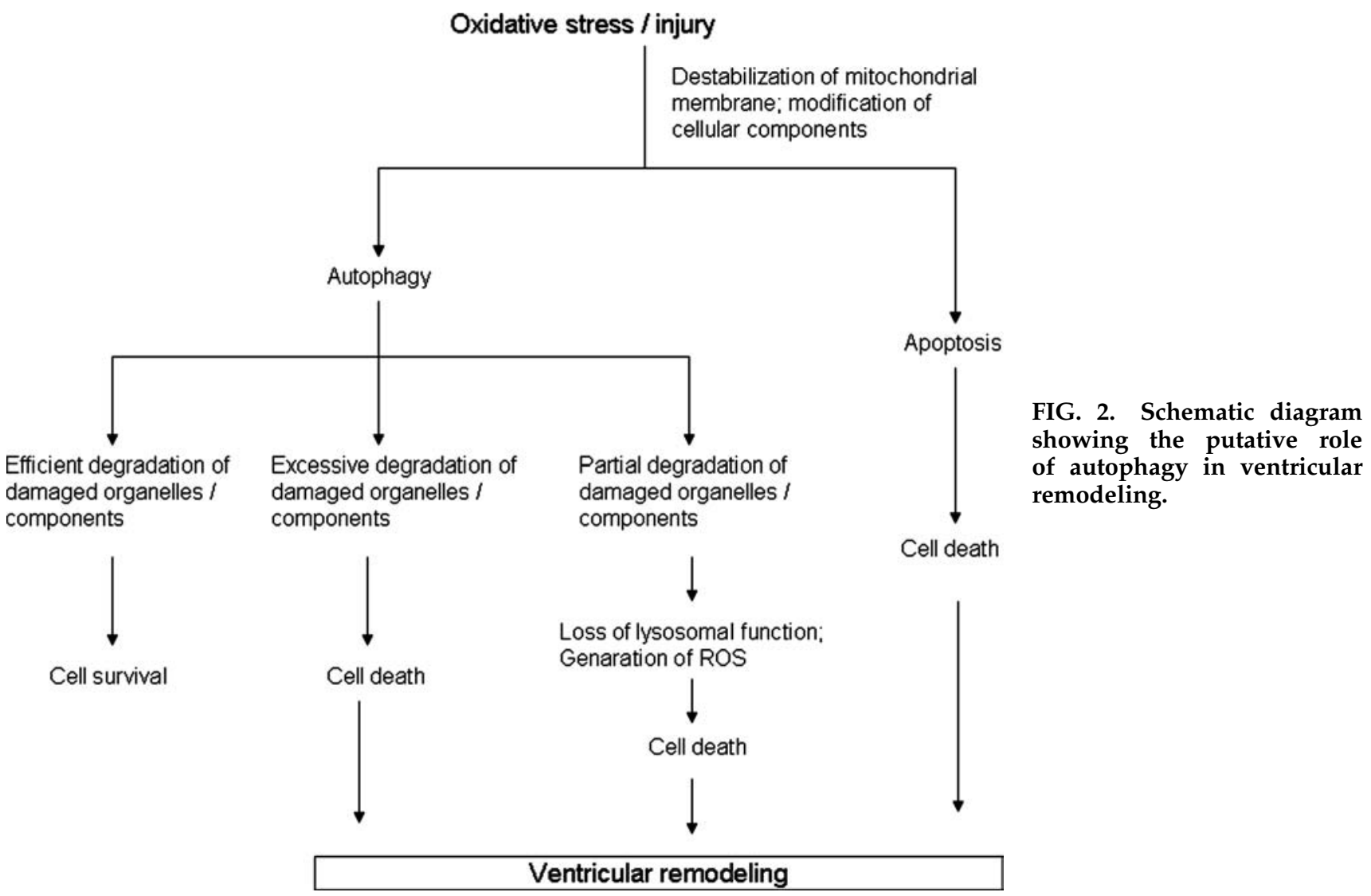

autophagy (89). In cardiac muscle, insulin antagonizes the activation of $\operatorname{AMPK}(5,31)$, and this appears to involve activation of the protein kinase Akt (74). Phosphorylation of AMPK subunits on Ser485 or Ser491 by Akt antagonizes AMPK activation via phosphorylation at Thr172 by LKB1 kinase (50). mTOR was shown to be associated with the mitochondrial outer membrane (122); thus, mTOR could sense changes in the ATP/AMP ratio (88) and control autophagy of individual mitochondria. These results suggest that AMPK may be required for the autophagy of mitochondria in particular (88).

The reperfusion-induced cardiac injury and autophagy were significantly attenuated in Beclin $1^{+/-}$mice (84). These results indicate that autophagy plays distinct roles during ischemia and reperfusion (i.e., autophagy elicited during ischemia is protective; however, the autophagy induced during the reperfusion phase may be detrimental). Ischemia/ reperfusion injury in cardiac HL-1 cells impaired the formation and downstream lysosomal degradation of autophagosomes (42). Overexpression of Beclin 1 enhanced autophagic flux after ischemia/reperfusion (I/R) and significantly reduced the activation of proapoptotic Bax, whereas knockdown of Beclin 1 by RNA interference increased Bax activation (42). These results demonstrate that autophagic flux is impaired at the level of both induction and degradation during stimulated ischemia/reperfusion, and enhancing autophagy stimulates a powerful protective mechanism against ischemia/reperfusion injury in cardiac cells (42). Bnip3 is a mitochondrial proapoptotic Bcl-2 protein expressed in the adult myocardium (44). Hamacher-Brady et al. $(43,44)$ demonstrated that Bnip3 contributes to cardiac I/R injury in a Bnip3-dependent manner. Bnip3 causes disruption of mitochondrial integrity, leading to enhanced superoxide production and the release of proapoptotic factors, such as cytochrome $c$ and apoptosis-inducing factor $(43,44)$. These results imply that Bnip3 contributes to myocardial injury, which triggers a protective stress response via upregulation of autophagy, which in turn helps with the removal of damaged mitochondria $(43,44)$.

Taken together, it is assumed that autophagy functions in the heart predominantly as a prosurvival mechanism during nutrient deprivation and other forms of cellular stress (Fig. 2). However, when autophagy is induced rigorously, the autophagic machinery might also be used for self-destruction. In this way, autophagic cell death can occur in a detectable number of cardiac cells and may lead finally to ventricular remodeling and heart failure (Fig. 2). Macroautophagy was shown to protect cells from apoptosis by removing the damaged mitochondria at an early stage (78). This protective macroautophagy is considered to be the crossroad between cell death and survival (125). Both autophagy and apoptosis are induced by death-associated protein kinase and tumor necrosis factor-related apoptosis-inducing ligand (104). At low levels of these factors, autophagy may be induced; however, if the activated autophagy is insufficient to remove the cellular damage, the intracellular level of the two death factors would remain high to induce cell death. Insufficient autophagy or partial degradation of damaged organelles or components causes the generation of ROS and loss of lysosomal function, leading to cell death and cardiac remodeling (75) (Fig. 2). 


\section{Therapeutic Implications}

Therapeutic advances for the modulation of autophagy in cardiovascular disease are very limited with the identification of many genes, and the intracellular regulators of autophagy are revealed to some extent. Because class III PI3 kinases are known to induce autophagy, several studies have implicated the use of inhibitors of the class III PI3 kinase pathway like wortmannin and 3-methyl adenine (41). However, these drugs are not suitable for therapeutic applications because they are highly toxic and are known to have multiple targets in vivo.

The serine/threonine kinase TOR is a key molecule in nutrient-sensing signal pathways in response to nutrients, amino acids, and mitogens; it participates in the regulation of autophagy. Rapamycin, an inhibitor of mTOR, was shown to confer preconditioning-like protection against $\mathrm{I} / \mathrm{R}$ injury in isolated mouse heart through the opening of mitochondrial $\mathrm{K}_{\text {ATP }}$ channels (61). Treatment with rapamycin reduced cardiac infarct size, although the infarct-limiting effect of rapamycin was not associated with improved recovery of ventricular function. Further, at low doses (25-100 nM), rapamycin reduces necrosis as well as apoptosis after simulated ischemia-reoxygenation in adult cardiomyocytes (61).

In a hamster model of human dilated cardiomyopathy, treatment with G-CSF significantly improved the autophagic degeneration of cardiomyocytes and cardiac remodeling, which is accompanied by the activation of Akt and signal transducer and activator of transcription-3, followed by a reduction in the level of myocardial tumor necrosis factor- $\alpha$ (133). Treatment with urocortin, an endogenous cardiac peptide, was shown to reduce autophagic and apoptotic cell death induced by I/R (143). The inhibition of autophagy by urocortin is mediated in part by inhibition of Beclin 1 expression, an effect mediated by activation of the PI3 kinase/ Akt pathway but which does not involve activation of p42/p44 MAPK (143).

In addition, treatment with propranolol, a nonselective beta blocker, and verapamil, calcium-channel blocker, has been shown to induce autophagy (4). However, treatment with $\beta$ adrenoreceptor agonist isoproterenol inhibited the formation of autophagic vacuoles (108). Because verapamil affects neither the $\beta$-adrenoreceptors nor the intracellular levels of the second-messenger cyclic AMP, the induction of cellular autophagy is suggested to be an early regulatory step in the adaptation of heart muscle mass to reduced work load (108).

Although autophagy has been shown to play both protective and detrimental roles in cardiac remodeling, therapeutic implications for the regulation of autophagy in ventricular remodeling induce skepticism, which is accentuated by our limited knowledge of the genes and intracellular regulators of autophagy.

\section{Conclusions}

Although autophagy is induced with several cardiac diseases like ischemic cardiomyopathy, dilated cardiomyopathy, cardiac hypertrophy, and ischemia/reperfusion injury, the role of autophagy under those conditions is controversial (i.e., whether the effect of autophagy is protective or detrimental for the heart). Although autophagy is nonselective, under oxidative conditions, it was shown to be an efficient mechanism in removing oxidatively damaged mitochondria, peroxisomes, and endoplasmic reticulum (66). Oxidative modification of cysteine residues in proteins influences the biologic activity of many proteins (149), and recently, Atg4 (specifically, cysteine 81 of Atg4) was shown to be regulated by a redox-dependent mechanism during starvation-induced autophagy (121). In vitro cell-free assays show that a reducing environment activates Atg4, whereas an oxidizing condition inhibits the activity of Atg4. Starvation induces the production of $\mathrm{H}_{2} \mathrm{O}_{2}$, which could inhibit the cleavage activity of Atg4 (121). Autophagy is considered an energy-efficient recycling system, as it supplies amino acids for the synthesis of essential proteins during starvation and thus helps to extend cell survival. This indicates that ROS produced during starvationinduced autophagy play an important role in the regulation of autophagy and, in turn, extend the life of cell. Further studies are required to explore the possibilities of redox regulation of other autophagic genes and the role of redox signalingmediated autophagy in the heart.

\section{Acknowledgments}

This study was supported in part by NIH HL 34360, HL22559, and HL 33889. The authors have no conflicting financial interests.

\section{Abbreviations}

4E-BP1, 4E-binding protein 1; AMP, adenosine monophosphate; $\mathrm{AMPK}$, adenosine monophosphate-activated protein kinase; ATP, adenosine triphosphate; DCM, dilated cardiomyopathy; GABARAP, $\gamma$-aminobutyric acid type A receptorassociated protein; GATE-16, Golgi-associated ATPase enhancer of $16 \mathrm{kDa}$; G-CSF, granulocyte colony-stimulating factor; GMP, guanosine monophosphate; HsAtg4A, human homologues of Atg4 or autophagin 2; HsAtg4B, human homologues of Atg4 or autophagin 1; Hsc73, heat-shock protein; $\mathrm{I} / \mathrm{R}$, ischemia/reperfusion; LAMP2a, lysosome-associated membrane protein type 2a; LC3, microtubule-associated protein light-chain 3; LC3-II, complex of LC3-I and PE; mTOR, mammalian target of rapamycin; $\mathrm{NADPH}$, nicotinamide adenine dinucleotide phosphate; PE, phosphatidylethanolamine; PI3-K, phosphatidylinositol 3-kinase; ROS, reactive oxygen species; S6K, S6 kinase; TUNEL, terminal dUTP nickend labeling.

\section{References}

1. Arner ES and Holmgren A. Physiological functions of thioredoxin and thioredoxin reductase. Eur J Biochem 267: 6102-6109, 2000.

2. Assuncao Guimaraes C and Linden R. Programmed cell deaths: apoptosis and alternative deathstyles. Eur J Biochem 271: 1638-1650, 2004.

3. Baehrecke EH. Autophagy: dual roles in life and death? Nat Rev Mol Cell Biol 6: 505-510, 2005.

4. Bahro $M$ and Pfeifer U. Short-term stimulation by propranolol and verapamil of cardiac cellular autophagy. J Mol Cell Cardiol 19: 1169-1178, 1987.

5. Beauloye C, Marsin AS, Bertrand L, Krause U, Hardie DG, Vanoverschelde JL, and Hue L. Insulin antagonizes AMPactivated protein kinase activation by ischemia or anoxia in rat hearts, without affecting total adenine nucleotides. FEBS Lett 505: 348-352, 2001.

6. Beugnet A, Tee AR, Taylor PM, and Proud CG. Regulation of targets of mTOR (mammalian target of rapamycin) 
signalling by intracellular amino acid availability. Biochem J 372: 555-566, 2003.

7. Biederbick A, Kern HF, and Elsasser HP. Monodansylcadaverine (MDC) is a specific in vivo marker for autophagic vacuoles. Eur J Cell Biol 66: 3-14, 1995.

8. Blommaart EF, Luiken JJ, Blommaart PJ, van Woerkom GM, and Meijer AJ. Phosphorylation of ribosomal protein S6 is inhibitory for autophagy in isolated rat hepatocytes. J Biol Chem 270: 2320-2326, 1995.

9. Blommaart EF, Krause U, Schellens JP, Vreeling-Sindelarova $\mathrm{H}$, and Meijer AJ. The phosphatidylinositol 3-kinase inhibitors wortmannin and LY294002 inhibit autophagy in isolated rat hepatocytes. Eur J Biochem 243: 240-246, 1997.

10. Brunk UT and Terman A. Lipofuscin: mechanisms of agerelated accumulation and influence on cell function. Free Radic Biol Med 33: 611-619, 2002.

11. Bruno P, Calastretti A, Priulla M, Asnaghi L, Scarlatti F, Nicolin A, and Canti G. Cell survival under nutrient stress is dependent on metabolic conditions regulated by Akt and not by autophagic vacuoles. Cell Signal 19: 2118-2126, 2007.

12. Buja LM, and Vela D. Cardiomyocyte death and renewal in the normal and diseased heart. Cardiovasc Pathol 17: 349374, 2008.

13. Burke AP and Virmani R. Pathophysiology of acute myocardial infarction. Med Clin North Am 91: 553-572, ix, 2007.

14. Chen Y, McMillan-Ward E, Kong J, Israels SJ, and Gibson SB. Oxidative stress induces autophagic cell death independent of apoptosis in transformed and cancer cells. Cell Death Differ 15: 171-182, 2008.

15. Codogno P and Meijer AJ. Autophagy and signaling: their role in cell survival and cell death. Cell Death Differ 12 (suppl 2): 1509-1518, 2005.

16. Cuervo AM. Autophagy: many paths to the same end. Mol Cell Biochem 263: 55-72, 2004.

17. Cuervo AM and Dice JF. Unique properties of lamp2a compared to other lamp2 isoforms. J Cell Sci 113: 44414450, 2000.

18. De Duve C and Wattiaux R. Functions of lysosomes. Annu Rev Physiol 28: 435-492, 1966.

19. Debnath J, Baehrecke EH, and Kroemer G. Does autophagy contribute to cell death? Autophagy 1: 66-74, 2005.

20. Dice JF. Chaperone-mediated autophagy. Autophagy 3: 295299, 2007.

21. Dice JF, Terlecky SR, Chiang HL, Olson TS, Isenman LD, Short-Russell SR, Freundlieb S, and Terlecky LJ. A selective pathway for degradation of cytosolic proteins by lysosomes. Semin Cell Biol 1: 449-455, 1990.

22. Diwan A and Dorn GW 2nd. Decompensation of cardiac hypertrophy: cellular mechanisms and novel therapeutic targets. Physiology (Bethesda) 22: 56-64, 2007.

23. Djavaheri-Mergny M, Amelotti M, Mathieu J, Besancon F, Bauvy C, Souquere S, Pierron G, and Codogno P. NFkappaB activation represses tumor necrosis factor-alphainduced autophagy. J Biol Chem 281: 30373-30382, 2006.

24. Elsasser A, Muller KD, Skwara W, Bode C, Kubler W, and Vogt AM. Severe energy deprivation of human hibernating myocardium as possible common pathomechanism of contractile dysfunction, structural degeneration and cell death. J Am Coll Cardiol 39: 1189-1198, 2002.

25. Elsasser A, Vogt AM, Nef H, Kostin S, Mollmann H, Skwara W, Bode C, Hamm C, and Schaper J. Human hibernating myocardium is jeopardized by apoptotic and autophagic cell death. J Am Coll Cardiol 43: 2191-2199, 2004.
26. Eskelinen EL. Roles of LAMP-1 and LAMP-2 in lysosome biogenesis and autophagy. Mol Aspects Med 27: 495-502, 2006.

27. Finkel T. Redox-dependent signal transduction. FEBS Lett 476: 52-54, 2000.

28. Finkel $\mathrm{T}$ and Holbrook NJ. Oxidants, oxidative stress and the biology of ageing. Nature 408: 239-247, 2000.

29. Fujiwara $\mathrm{H}$ and Takemura G. [Recent advances and future issues in basic research of heart failure]. Nippon Rinsho 65(suppl 4): 9-16, 2007.

30. Gamaley IA and Klyubin IV. Roles of reactive oxygen species: signaling and regulation of cellular functions. Int Rev Cytol 188: 203-255, 1999.

31. Gamble J and Lopaschuk GD. Insulin inhibition of $5^{\prime}$ adenosine monophosphate-activated protein kinase in the heart results in activation of acetyl coenzyme A carboxylase and inhibition of fatty acid oxidation. Metabolism 46: 12701274, 1997.

32. George MD, Baba M, Scott SV, Mizushima N, Garrison BS, Ohsumi Y, and Klionsky DJ. Apg5p functions in the sequestration step in the cytoplasm-to-vacuole targeting and macroautophagy pathways. Mol Biol Cell 11: 969-982, 2000.

33. Giles NM, Gutowski NJ, Giles GI, and Jacob C. Redox catalysts as sensitisers towards oxidative stress. FEBS Lett 535: 179-182, 2003.

34. Giles NM, Watts AB, Giles GI, Fry FH, Littlechild JA, and Jacob C. Metal and redox modulation of cysteine protein function. Chem Biol 10: 677-693, 2003.

35. Gomez-Santos C, Ferrer I, Santidrian AF, Barrachina M, Gil J, and Ambrosio S. Dopamine induces autophagic cell death and alpha-synuclein increase in human neuroblastoma SH-SY5Y cells. J Neurosci Res 73: 341-350, 2003.

36. Gordon PB, Hoyvik H, and Seglen PO. Prelysosomal and lysosomal connections between autophagy and endocytosis. Biochem J 283: 361-369, 1992.

37. Goswami SK and Das DK. Autophagy in the myocardium: dying for survival? Exp Clin Cardiol 11: 183-188, 2006.

38. Gustafsson AB and Gottlieb RA. Recycle or die: the role of autophagy in cardioprotection. J Mol Cell Cardiol 44: 654661, 2008.

39. Gutierrez MG, Munafo DB, Beron W, and Colombo MI. Rab7 is required for the normal progression of the autophagic pathway in mammalian cells. J Cell Sci 117: 26872697, 2004.

40. Gutierrez MG, Master SS, Singh SB, Taylor GA, Colombo MI, and Deretic V. Autophagy is a defense mechanism inhibiting BCG and Mycobacterium tuberculosis survival in infected macrophages. Cell 119: 753-766, 2004.

41. Hamacher-Brady A, Brady NR, and Gottlieb RA. The interplay between pro-death and pro-survival signaling pathways in myocardial ischemia/reperfusion injury: apoptosis meets autophagy. Cardiovasc Drugs Ther 20: 445-462, 2006.

42. Hamacher-Brady A, Brady NR, and Gottlieb RA. Enhancing macroautophagy protects against ischemia/reperfusion injury in cardiac myocytes. J Biol Chem 281: 29776-29787, 2006.

43. Hamacher-Brady A, Brady NR, Gottlieb RA, and Gustafsson AB. Autophagy as a protective response to Bnip3-mediated apoptotic signaling in the heart. Autophagy 2: 307-309, 2006.

44. Hamacher-Brady A, Brady NR, Logue SE, Sayen MR, Jinno M, Kirshenbaum LA, Gottlieb RA, and Gustafsson AB. Response to myocardial ischemia/reperfusion injury involves Bnip3 and autophagy. Cell Death Differ 14: 146-157, 2007. 
45. Hardie DG. The AMP-activated protein kinase pathway: new players upstream and downstream. J Cell Sci 117: 5479-5487, 2004.

46. Hein S, Elsasser A, Kostin S, Zimmermann R, and Schaper J. Functional disturbances due to structural remodeling in the failing human heart. Arch Mal Coeur Vaiss 95: 815-820, 2002.

47. Hein S, Arnon E, Kostin S, Schonburg M, Elsasser A, Polyakova V, Bauer EP, Klovekorn WP, and Schaper J. Progression from compensated hypertrophy to failure in the pressure-overloaded human heart: structural deterioration and compensatory mechanisms. Circulation 107: 984991, 2003.

48. Hensley K, Robinson KA, Gabbita SP, Salsman S, and Floyd RA. Reactive oxygen species, cell signaling, and cell injury. Free Radic Biol Med 28: 1456-1462, 2000.

49. Hetz CA. ER stress signaling and the BCL-2 family of proteins: from adaptation to irreversible cellular damage. Antioxid Redox Signal 9: 2345-2355, 2007.

50. Horman S, Vertommen D, Heath R, Neumann D, Mouton V, Woods A, Schlattner U, Wallimann T, Carling D, Hue L, and Rider MH. Insulin antagonizes ischemia-induced Thr172 phosphorylation of AMP-activated protein kinase alphasubunits in heart via hierarchical phosphorylation of Ser485/491. J Biol Chem 281: 5335-5340, 2006.

51. Hoyer-Hansen $M$ and Jaattela $M$. Connecting endoplasmic reticulum stress to autophagy by unfolded protein response and calcium. Cell Death Differ 14: 1576-1582, 2007.

52. Jager S, Bucci C, Tanida I, Ueno T, Kominami E, Saftig P, and Eskelinen EL. Role for Rab7 in maturation of late autophagic vacuoles. J Cell Sci 117: 4837-4848, 2004.

53. Juhasz G and Neufeld TP. Autophagy: a forty-year search for a missing membrane source. PLoS Biol 4: e36, 2006.

54. Kabeya Y, Mizushima N, Yamamoto A, Oshitani-Okamoto S, Ohsumi Y, and Yoshimori T. LC3, GABARAP and GATE16 localize to autophagosomal membrane depending on form-II formation. J Cell Sci 117: 2805-2812, 2004.

55. Kabeya Y, Mizushima N, Ueno T, Yamamoto A, Kirisako T, Noda T, Kominami E, Ohsumi Y, and Yoshimori T. LC3, a mammalian homologue of yeast Apg8p, is localized in autophagosome membranes after processing. EMBO J 19: 5720-5728, 2000.

56. Kamada Y, Funakoshi T, Shintani T, Nagano K, Ohsumi M, and Ohsumi Y. Tor-mediated induction of autophagy via an Apg1 protein kinase complex. J Cell Biol 150: 1507-1513, 2000.

57. Katori T, Donzelli S, Tocchetti CG, Miranda KM, Cormaci G, Thomas DD, Ketner EA, Lee MJ, Mancardi D, Wink DA, Kass DA, and Paolocci N. Peroxynitrite and myocardial contractility: in vivo versus in vitro effects. Free Radic Biol Med 41: 1606-1618, 2006.

58. Katz ML and Robison WG Jr. What is lipofuscin? defining characteristics and differentiation from other autofluorescent lysosomal storage bodies. Arch Gerontol Geriatr 34: 169-184, 2002.

59. Kaushik S and Cuervo AM. Autophagy as a cell-repair mechanism: activation of chaperone-mediated autophagy during oxidative stress. Mol Aspects Med 27: 444-454, 2006.

60. Kern JC and Kehrer JP. Free radicals and apoptosis: relationships with glutathione, thioredoxin, and the BCL family of proteins. Front Biosci 10: 1727-1738, 2005.

61. Khan S, Salloum F, Das A, Xi L, Vetrovec GW, and Kukreja RC. Rapamycin confers preconditioning-like protection against ischemia-reperfusion injury in isolated mouse heart and cardiomyocytes. J Mol Cell Cardiol 41: 256-264, 2006.

62. Kiffin R, Bandyopadhyay U, and Cuervo AM. Oxidative stress and autophagy. Antioxid Redox Signal 8: 152-162, 2006.

63. Kiffin R, Christian C, Knecht E, and Cuervo AM. Activation of chaperone-mediated autophagy during oxidative stress. Mol Biol Cell 15: 4829-4840, 2004.

64. Kihara A, Noda T, Ishihara N, and Ohsumi Y. Two distinct Vps34 phosphatidylinositol 3-kinase complexes function in autophagy and carboxypeptidase $\mathrm{Y}$ sorting in Saccharomyces cerevisiae. J Cell Biol 152: 519-530, 2001.

65. Kihara A, Kabeya Y, Ohsumi Y, and Yoshimori T. Beclinphosphatidylinositol 3-kinase complex functions at the trans-Golgi network. EMBO Rep 2: 330-335, 2001.

66. Kim I, Rodriguez-Enriquez S, and Lemasters JJ. Selective degradation of mitochondria by mitophagy. Arch Biochem Biophys 462: 245-253, 2007.

67. Kirisako T, Baba M, Ishihara N, Miyazawa K, Ohsumi M, Yoshimori T, Noda T, and Ohsumi Y. Formation process of autophagosome is traced with Apg8/Aut7p in yeast. J Cell Biol 147: 435-446, 1999.

68. Kirkland RA, Adibhatla RM, Hatcher JF, and Franklin JL. Loss of cardiolipin and mitochondria during programmed neuronal death: evidence of a role for lipid peroxidation and autophagy. Neuroscience 115: 587-602, 2002.

69. Kissova I, Deffieu M, Samokhvalov V, Velours G, Bessoule JJ, Manon S, and Camougrand N. Lipid oxidation and autophagy in yeast. Free Radic Biol Med 41: 1655-1661, 2006.

70. Klionsky DJ and Emr SD. Autophagy as a regulated pathway of cellular degradation. Science 290: 1717-1721, 2000.

71. Klionsky DJ, Cregg JM, Dunn WA Jr, Emr SD, Sakai Y, Sandoval IV, Sibirny A, Subramani S, Thumm M, Veenhuis $\mathrm{M}$, and Ohsumi Y. A unified nomenclature for yeast autophagy-related genes. Dev Cell 5: 539-545, 2003.

72. Knaapen MW, Davies MJ, De Bie M, Haven AJ, Martinet W, and Kockx MM. Apoptotic versus autophagic cell death in heart failure. Cardiovasc Res 51: 304-312, 2001.

73. Kostin S, Pool L, Elsasser A, Hein S, Drexler HC, Arnon E, Hayakawa Y, Zimmermann R, Bauer E, Klovekorn WP, and Schaper J. Myocytes die by multiple mechanisms in failing human hearts. Circ Res 92: 715-724, 2003.

74. Kovacic S, Soltys CL, Barr AJ, Shiojima I, Walsh K, and Dyck JR. Akt activity negatively regulates phosphorylation of AMP-activated protein kinase in the heart. J Biol Chem 278: 39422-39427, 2003.

75. Kroemer G and Jaattela M. Lysosomes and autophagy in cell death control. Nat Rev Cancer 5: 886-897, 2005.

76. Kuma A, Hatano M, Matsui M, Yamamoto A, Nakaya H, Yoshimori T, Ohsumi Y, Tokuhisa T, and Mizushima N. The role of autophagy during the early neonatal starvation period. Nature 432: 1032-1036, 2004.

77. Kurz T, Terman A, Gustafsson B, and Brunk UT. Lysosomes and oxidative stress in aging and apoptosis. Biochim Biophys Acta 1780: 1291-1303, 2008.

78. Lemasters JJ, Nieminen AL, Qian T, Trost LC, Elmore SP, Nishimura Y, Crowe RA, Cascio WE, Bradham CA, Brenner DA, and Herman B. The mitochondrial permeability transition in cell death: a common mechanism in necrosis, apoptosis and autophagy. Biochim Biophys Acta 1366: 177196, 1998.

79. Levine B and Yuan J. Autophagy in cell death: an innocent convict? J Clin Invest 115: 2679-2688, 2005.

80. Liang XH, Yu J, Brown K, and Levine B. Beclin 1 contains a leucine-rich nuclear export signal that is required for its 
autophagy and tumor suppressor function. Cancer Res 61: 3443-3449, 2001.

81. Liang XH, Jackson S, Seaman M, Brown K, Kempkes B, Hibshoosh $\mathrm{H}$, and Levine B. Induction of autophagy and inhibition of tumorigenesis by beclin 1 . Nature 402: 672-676, 1999.

82. Liu Z and Lenardo MJ. Reactive oxygen species regulate autophagy through redox-sensitive proteases. Dev Cell 12: 484-485, 2007.

83. Marino G, Uria JA, Puente XS, Quesada V, Bordallo J, and Lopez-Otin C. Human autophagins, a family of cysteine proteinases potentially implicated in cell degradation by autophagy. J Biol Chem 278: 3671-3678, 2003.

84. Massey A, Kiffin R, and Cuervo AM. Pathophysiology of chaperone-mediated autophagy. Int J Biochem Cell Biol 36: 2420-2434, 2004.

85. Matsui $\mathrm{Y}$, Takagi H, Qu X, Abdellatif M, Sakoda H, Asano $\mathrm{T}$, Levine B, and Sadoshima J. Distinct roles of autophagy in the heart during ischemia and reperfusion: roles of AMPactivated protein kinase and Beclin 1 in mediating autophagy. Circ Res 100: 914-922, 2007.

86. Matsui Y, Kyoi S, Takagi H, Hsu CP, Hariharan N, Ago T, Vatner SF, and Sadoshima J. Molecular mechanisms and physiological significance of autophagy during myocardial ischemia and reperfusion. Autophagy 4: 409-415, 2008.

87. Mearini G, Schlossarek S, Willis MS, and Carrier L. Ubiquitin-proteasome system in cardiac dysfunction. Biochim Biophys Acta 1782: 749-763, 2008.

88. Meijer AJ and Dubbelhuis PF. Amino acid signalling and the integration of metabolism. Biochem Biophys Res Commun 313: 397-403, 2004

89. Meijer AJ and Codogno P. Signalling and autophagy regulation in health, aging and disease. Mol Aspects Med 27: 411-425, 2006.

90. Mijaljica D, Prescott M, and Devenish RJ. Different fates of mitochondria: alternative ways for degradation? Autophagy 3: 4-9, 2007.

91. Mistiaen WP, Somers P, Knaapen MW, and Kockx MM. Autophagy as mechanism for cell death in degenerative aortic valve disease. Autophagy 2: 221-223, 2006.

92. Mizushima N. Methods for monitoring autophagy. Int J Biochem Cell Biol 36: 2491-2502, 2004.

93. Mizushima N, Ohsumi Y, and Yoshimori T. Autophagosome formation in mammalian cells. Cell Struct Funct 27: 421-429, 2002.

94. Mizushima N, Yamamoto A, Matsui M, Yoshimori T, and Ohsumi Y. In vivo analysis of autophagy in response to nutrient starvation using transgenic mice expressing a fluorescent autophagosome marker. Mol Biol Cell 15: 1101-1111, 2004.

95. Mizushima N, Noda T, Yoshimori T, Tanaka Y, Ishii T, George MD, Klionsky DJ, Ohsumi M, and Ohsumi Y. A protein conjugation system essential for autophagy. Nature 395: 395-398, 1998.

96. Mizushima N, Yamamoto A, Hatano M, Kobayashi Y, Kabeya Y, Suzuki K, Tokuhisa T, Ohsumi Y, and Yoshimori T. Dissection of autophagosome formation using Apg5deficient mouse embryonic stem cells. J Cell Biol 152: 657668, 2001.

97. Mortimore GE, Lardeux BR, and Adams CE. Regulation of microautophagy and basal protein turnover in rat liver: effects of short-term starvation. J Biol Chem 263: 2506-2512, 1988.
98. Murdoch CE, Zhang M, Cave AC, and Shah AM. NADPH oxidase-dependent redox signalling in cardiac hypertrophy, remodelling and failure. Cardiovasc Res 71: 208-215, 2006.

99. Mustacich D and Powis G. Thioredoxin reductase. Biochem J 346 Pt 1: 1-8, 2000.

100. Nakai A, Yamaguchi O, Takeda T, Higuchi Y, Hikoso S, Taniike M, Omiya S, Mizote I, Matsumura Y, Asahi M, Nishida K, Hori M, Mizushima N, and Otsu K. The role of autophagy in cardiomyocytes in the basal state and in response to hemodynamic stress. Nat Med 13: 619-624, 2007.

101. Neufeld TP. Contribution of Atg1-dependent autophagy to TOR-mediated cell growth and survival. Autophagy 3: 477479, 2007.

102. Obara K, Sekito T, and Ohsumi Y. Assortment of phosphatidylinositol 3-kinase complexes: Atg14p directs association of complex I to the pre-autophagosomal structure in Saccharomyces cerevisiae. Mol Biol Cell 17: 1527-1539, 2006.

103. Ollinger K and Roberg K. Nutrient deprivation of cultured rat hepatocytes increases the desferrioxamine-available iron pool and augments the sensitivity to hydrogen peroxide. J Biol Chem 272: 23707-23711, 1997.

104. Paglin S, Hollister T, Delohery T, Hackett N, McMahill M, Sphicas E, Domingo D, and Yahalom J. A novel response of cancer cells to radiation involves autophagy and formation of acidic vesicles. Cancer Res 61: 439-444, 2001.

105. Pai EF and Schulz GE. The catalytic mechanism of glutathione reductase as derived from x-ray diffraction analyses of reaction intermediates. J Biol Chem 258: 1752-1757, 1983.

106. Pattingre S, Espert L, Biard-Piechaczyk M, and Codogno P. Regulation of macroautophagy by $\mathrm{mTOR}$ and Beclin 1 complexes. Biochimie 90: 313-323, 2008.

107. Percival MD, Ouellet M, Campagnolo C, Claveau D, and Li $\mathrm{C}$. Inhibition of cathepsin $\mathrm{K}$ by nitric oxide donors: evidence for the formation of mixed disulfides and a sulfenic acid. Biochemistry 38: 13574-13583, 1999.

108. Pfeifer U, Fohr J, Wilhelm W, and Dammrich J. Short-term inhibition of cardiac cellular autophagy by isoproterenol. J Mol Cell Cardiol 19: 1179-1184, 1987.

109. Powell SR. The ubiquitin-proteasome system in cardiac physiology and pathology. Am J Physiol Heart Circ Physiol 291: H1-H19, 2006.

110. Ravikumar B, Vacher C, Berger Z, Davies JE, Luo S, Oroz LG, Scaravilli F, Easton DF, Duden R, O'Kane CJ, and Rubinsztein DC. Inhibition of mTOR induces autophagy and reduces toxicity of polyglutamine expansions in fly and mouse models of Huntington disease. Nat Genet 36: 585-595, 2004.

111. Sadoshima J. The role of autophagy during ischemia/ reperfusion. Autophagy 4: 402-403, 2008.

112. Sagiv Y, Legesse-Miller A, Porat A, and Elazar Z. GATE-16, a membrane transport modulator, interacts with NSF and the Golgi v-SNARE GOS-28. EMBO J 19: 1494-1504, 2000.

113. Saijo M, Takemura G, Koda M, Okada H, Miyata S, Ohno Y, Kawasaki M, Tsuchiya K, Nishigaki K, Minatoguchi S, Goto K, and Fujiwara H. Cardiomyopathy with prominent autophagic degeneration, accompanied by an elevated plasma brain natriuretic peptide level despite the lack of overt heart failure. Intern Med 43: 700-703, 2004.

114. Salvador N, Aguado C, Horst M, and Knecht E. Import of a cytosolic protein into lysosomes by chaperone-mediated autophagy depends on its folding state. J Biol Chem 275: 27447-27456, 2000. 
115. Samari HR and Seglen PO. Inhibition of hepatocytic autophagy by adenosine, aminoimidazole-4-carboxamide riboside, and N6-mercaptopurine riboside: evidence for involvement of amp-activated protein kinase. J Biol Chem 273: 23758-23763, 1998.

116. Samari HR, Moller MT, Holden L, Asmyhr T, and Seglen PO. Stimulation of hepatocytic AMP-activated protein kinase by okadaic acid and other autophagy-suppressive toxins. Biochem J 386: 237-244, 2005.

117. Sawyer DB, Siwik DA, Xiao L, Pimentel DR, Singh K, and Colucci WS. Role of oxidative stress in myocardial hypertrophy and failure. J Mol Cell Cardiol 34: 379-388, 2002.

118. Scarlatti F, Granata R, Meijer AJ, and Codogno P. Does autophagy have a license to kill mammalian cells? Cell Death Differ 16: 12-20, 2009.

119. Scherz-Shouval R and Elazar Z. ROS, mitochondria and the regulation of autophagy. Trends Cell Biol 17: 422-427, 2007.

120. Scherz-Shouval R, Shvets E, and Elazar Z. Oxidation as a post-translational modification that regulates autophagy. Autophagy 3: 371-373, 2007.

121. Scherz-Shouval R, Shvets E, Fass E, Shorer H, Gil L, and Elazar Z. Reactive oxygen species are essential for autophagy and specifically regulate the activity of Atg4. EMBO J 26: 1749-1760, 2007.

122. Schieke SM, Phillips D, McCoy JP Jr, Aponte AM, Shen RF, Balaban RS, and Finkel T. The mammalian target of rapamycin (mTOR) pathway regulates mitochondrial oxygen consumption and oxidative capacity. J Biol Chem 281: 27643-27652, 2006.

123. Scott RC, Schuldiner O, and Neufeld TP. Role and regulation of starvation-induced autophagy in the Drosophila fat body. Dev Cell 7: 167-178, 2004.

124. Scott SV, Nice DC 3rd, Nau JJ, Weisman LS, Kamada Y, Keizer-Gunnink I, Funakoshi T, Veenhuis M, Ohsumi Y, and Klionsky DJ. Apg13p and Vac8p are part of a complex of phosphoproteins that are required for cytoplasm to vacuole targeting. J Biol Chem 275: 25840-25849, 2000.

125. Shimizu S, Kanaseki T, Mizushima N, Mizuta T, ArakawaKobayashi S, Thompson CB, and Tsujimoto Y. Role of Bcl-2 family proteins in a non-apoptotic programmed cell death dependent on autophagy genes. Nat Cell Biol 6: 1221-1228, 2004.

126. Shimomura H, Terasaki F, Hayashi T, Kitaura Y, Isomura $\mathrm{T}$, and Suma H. Autophagic degeneration as a possible mechanism of myocardial cell death in dilated cardiomyopathy. Jpn Circ J 65: 965-968, 2001.

127. Shintani T and Klionsky DJ. Autophagy in health and disease: a double-edged sword. Science 306: 990-995, 2004.

128. Somers $P$, Knaapen M, Kockx M, van Cauwelaert P, Bortier $\mathrm{H}$, and Mistiaen W. Histological evaluation of autophagic cell death in calcified aortic valve stenosis. J Heart Valve Dis 15: 43-47; discussion 48, 2006.

129. Sugawara K, Suzuki NN, Fujioka Y, Mizushima N, Ohsumi $Y$, and Inagaki F. Structural basis for the specificity and catalysis of human Atg4B responsible for mammalian autophagy. J Biol Chem 280: 40058-40065, 2005.

130. Sybers HD, Ingwall J, and DeLuca M. Autophagy in cardiac myocytes. Recent Adv Stud Cardiac Struct Metab 12: 453-463, 1976.

131. Takagi H, Matsui Y, and Sadoshima J. The role of autophagy in mediating cell survival and death during ischemia and reperfusion in the heart. Antioxid Redox Signal 9: 13731381, 2007.
132. Takagi H, Matsui $Y$, Hirotani S, Sakoda H, Asano T, and Sadoshima J. AMPK mediates autophagy during myocardial ischemia in vivo. Autophagy 3: 405-407, 2007.

133. Takemura G, Miyata S, Kawase Y, Okada H, Maruyama R, and Fujiwara H. Autophagic degeneration and death of cardiomyocytes in heart failure. Autophagy 2: 212-214, 2006.

134. Tanaka Y, Guhde G, Suter A, Eskelinen EL, Hartmann D, Lullmann-Rauch R, Janssen PM, Blanz J, von Figura K, and Saftig P. Accumulation of autophagic vacuoles and cardiomyopathy in LAMP-2-deficient mice. Nature 406: 902 906, 2000.

135. Tanida I, Ueno T, and Kominami E. LC3 conjugation system in mammalian autophagy. Int J Biochem Cell Biol 36: 2503-2518, 2004.

136. Tanida I, Minematsu-Ikeguchi N, Ueno T, and Kominami E. Lysosomal turnover, but not a cellular level, of endogenous LC3 is a marker for autophagy. Autophagy 1: 84-91, 2005.

137. Tanida I, Sou YS, Ezaki J, Minematsu-Ikeguchi N, Ueno T, and Kominami E. HsAtg4B/HsApg4B/autophagin-1 cleaves the carboxyl termini of three human Atg8 homologues and delipidates microtubule-associated protein light chain 3-and GABAA receptor-associated protein-phospholipid conjugates. J Biol Chem 279: 36268-36276, 2004.

138. Terman A and Brunk UT. Lipofuscin. Int J Biochem Cell Biol 36: 1400-1404, 2004.

139. Terman A and Brunk UT. Autophagy in cardiac myocyte homeostasis, aging, and pathology. Cardiovasc Res 68: 355365, 2005.

140. Terman A, Gustafsson B, and Brunk UT. Mitochondrial damage and intralysosomal degradation in cellular aging. Mol Aspects Med 27: 471-482, 2006.

141. Terman A, Gustafsson B, and Brunk UT. Autophagy, organelles and ageing. J Pathol 211: 134-143, 2007.

142. Thorpe GW, Fong CS, Alic N, Higgins VJ, and Dawes IW. Cells have distinct mechanisms to maintain protection against different reactive oxygen species: oxidative-stressresponse genes. Proc Natl Acad Sci U S A 101: 6564-6569, 2004.

143. Valentim L, Laurence KM, Townsend PA, Carroll CJ Soond S, Scarabelli TM, Knight RA, Latchman DS, and Stephanou A. Urocortin inhibits Beclin1-mediated autophagic cell death in cardiac myocytes exposed to ischaemia/ reperfusion injury. J Mol Cell Cardiol 40: 846-852, 2006.

144. Wan FY, Wang YN, and Zhang GJ. The influence of oxidation of membrane thiol groups on lysosomal proton permeability. Biochem J 360: 355-362, 2001.

145. Wang H, Bedford FK, Brandon NJ, Moss SJ, and Olsen RW. GABA(A)-receptor-associated protein links GABA(A) receptors and the cytoskeleton. Nature 397: 69-72, 1999.

146. Wang Z, Wilson WA, Fujino MA, and Roach PJ. Antagonistic controls of autophagy and glycogen accumulation by Snf1p, the yeast homolog of AMP-activated protein kinase, and the cyclin-dependent kinase Pho85p. Mol Cell Biol 21: 5742-5752, 2001.

147. Winchester BG. Lysosomal membrane proteins. Eur J Paediatr Neurol 5(suppl A): 11-19, 2001.

148. Xiong Y, Contento AL, Nguyen PQ, and Bassham DC. Degradation of oxidized proteins by autophagy during oxidative stress in Arabidopsis. Plant Physiol 143: 291-299, 2007.

149. Xu D, Rovira, II, and Finkel T. Oxidants painting the cysteine chapel: redox regulation of PTPs. Dev Cell 2: 251-252, 2002. 
150. Xue L, Fletcher GC, and Tolkovsky AM. Autophagy is activated by apoptotic signalling in sympathetic neurons: an alternative mechanism of death execution. Mol Cell Neurosci 14: 180-198, 1999.

151. Yan L, Sadoshima J, Vatner DE, and Vatner SF. Autophagy: a novel protective mechanism in chronic ischemia. Cell Cycle 5: 1175-1177, 2006.

152. Yan L, Vatner DE, Kim SJ, Ge H, Masurekar M, Massover WH, Yang G, Matsui Y, Sadoshima J, and Vatner SF. Autophagy in chronically ischemic myocardium. Proc Natl Acad Sci U S A 102: 13807-13812, 2005.

153. Yang YP, Liang ZQ, Gu ZL, and Qin ZH. Molecular mechanism and regulation of autophagy. Acta Pharmacol Sin 26: 1421-1434, 2005.

154. Yorimitsu T and Klionsky DJ. Autophagy: molecular machinery for self-eating. Cell Death Differ 12(suppl 2): 15421552, 2005.

155. Yu L, Wan F, Dutta S, Welsh S, Liu Z, Freundt E, Baehrecke $\mathrm{EH}$, and Lenardo M. Autophagic programmed cell death by selective catalase degradation. Proc Natl Acad Sci U S A 103: 4952-4957, 2006.
156. Zeng $\mathrm{X}$, Overmeyer $\mathrm{JH}$, and Maltese WA. Functional specificity of the mammalian Beclin-Vps34 PI 3-kinase complex in macroautophagy versus endocytosis and lysosomal enzyme trafficking. J Cell Sci 119: 259-270, 2006.

157. Zhu H, Tannous P, Johnstone JL, Kong Y, Shelton JM, Richardson JA, Le V, Levine B, Rothermel BA, and Hill JA. Cardiac autophagy is a maladaptive response to hemodynamic stress. J Clin Invest 117: 1782-1793, 2007.

Address correspondence to: Dipak K. Das, Ph.D., Sc.D, FAHA Cardiovascular Research Center University of Connecticut School of Medicine Farmington, CT 06030-1110

E-mail: DDAS@NEURON.UCHC.EDU

Date of first submission to ARS Central, February 21, 2009; date of final revised submission, February 21, 2009; date of acceptance, February 25, 2009. 